\title{
Subgrain boundary analyses in deformed orthopyroxene by TEM/STEM with EBSD-FIB sample preparation technique
}

\author{
Toshihiro Kogure ${ }^{1 *}$, Hugues Raimbourg ${ }^{2}$, Akihito Kumamoto ${ }^{3}$, Eiko Fujii ${ }^{1}$ and Yuichi Ikuhara ${ }^{3}$
}

\begin{abstract}
High-resolution structure analyses using electron beam techniques have been performed for the investigation of subgrain boundaries (SGBs) in deformed orthopyroxene (Opx) in mylonite from Hidaka Metamorphic Belt, Hokkaido, Japan, to understand ductile deformation mechanism of silicate minerals in shear zones. Scanning electron microscopy (SEM) and electron backscatter diffraction (EBSD) analysis of Opx porphyroclasts in the mylonitic rock indicated that the crystal orientation inside the Opx crystals gradually changes by rotation about the $b$-axis by SGBs and crystal folding. In order to observe the SGBs along the $b$-axis by transmission electron microscopy (TEM) or scanning TEM (STEM), the following sample preparation protocol was adopted. First, petrographic thin sections were slightly etched with hydrofluoric acid to identify SGBs in SEM. The Opx crystals whose $b$-axes were oriented close to the normal of the surface were identified by EBSD, and the areas containing SGBs were picked and thinned for (S) TEM analysis with a focused ion beam instrument with micro-sampling system. High-resolution TEM imaging of the SGBs in Opx revealed various boundary structures from a periodic array of dissociated (100) [001] edge dislocations to partially or completely incoherent crystals, depending on the misorientation angle. Atomic-resolution STEM imaging clearly confirmed the formation of clinopyroxene (Cpx) structure between the dissociated partial dislocations. Moreover, $X$-ray microanalysis in STEM revealed that the Cpx contains a considerable amount of calcium replacing iron. Such chemical inhomogeneity may limit glide motion of the dislocation and eventually the plastic deformation of the Opx porphyroclasts at a low temperature. Chemical profiles across the high-angle incoherent SGB also showed an enrichment of the latter in calcium at the boundary, suggesting that SGBs are an efficient diffusion pathway of calcium out of host Opx grain during cooling.
\end{abstract}

Keywords: Deformation; Dislocation; Pyroxene; Subgrain boundary; TEM/STEM

\section{Background}

The interplay between deformation, grain size decrease, and mechanical weakening is considered as a major process to account for the localization of the ductile deformation of rocks in the shear zones (e.g., Boullier and Gueguen 1975; Rice 1976; Poirier 1980; Braun et al. 1999; Furusho and Kanagawa 1999; Precigout et al. 2007; Raimbourg et al. 2008). Though the operating microscopic mechanisms are not constant but depend on strain rate and temperature (Hirth and Tullis 1992; Poirier 1995), grain size reduction of constituting minerals involves the creation of a large area

\footnotetext{
* Correspondence: kogure@eps.s.u-tokyo.ac.jp

${ }^{1}$ Department of Earth and Planetary Science, Graduate School of Science, The University of Tokyo, 7-3-1 Hongo, Bunkyo-ku, Tokyo 113-0033, Japan Full list of author information is available at the end of the article
}

of grain boundaries (GBs) and is therefore ultimately controlled by GB structure and properties. One possible mechanism for the grain size reduction is the formation of subgrain boundaries (SGBs) and their evolution into general GBs with progressive misorientation angles between the two sides of the SGBs. From the observation of recrystallization textures, the transition from SGBs with regular arrays of dislocations within a single crystal to GBs incoherently separating two distinct crystals is often associated with a misorientation angle of $10^{\circ}$ to $15^{\circ}$ (e.g., Poirier and Nicolas 1975; White 1977; Guillopé and Poirier 1979; White and Mawer 1988), although for plagioclase, Fitz Gerald et al. (1983) proposed critical misorientation values below $5^{\circ}$. The general idea is that above a certain 
critical misorientation angle, dislocations should be too closely spaced for coherent crystal to be present between them (Read 1953). Such theoretical predictions can be evaluated by direct observations of the boundaries by transmission electron microscopy (TEM). Heinemann et al. (2005) followed, using high-resolution TEM (HRTEM), the evolution of synthetic SGBs in olivine with increasing misorientation. In natural orthopyroxene, although TEM works on dislocations and SGBs are plenty (e.g., Kohlstedt and Vander Sande 1973; McLaren and Etheridge 1976, 1980), there is no systematic investigation of the transition from SGBs to true GB which is the objective of the present work.

Generally, rocks or minerals are initially characterized by making a petrographic thin section of rocks polished to a thickness of $30 \mu \mathrm{m}$ on a glass slide and observing them with polarized light microscopy and/or scanning electron microscopy (SEM). For detailed characterizations of the minerals using TEM, a sample preparation technique for the TEM observation at specific areas in the petrographic thin sections, for instance those containing SGBs in the present case, is necessary. In the past, it was almost impossible or required tremendous efforts to prepare such TEM specimens, especially in case that the density of SGBs is low. However, this problem has been solved by the invention and commercialization of the focused ion beam (FIB) instruments with the micro-sampling function (Kamino et al. 2005) and, for more specific TEM specimens, with the assist of electron backscatter diffraction (EBSD) analysis in a SEM. Recently, we reported and discussed the SGB structures in naturally deformed orthopyroxene $\left((\mathrm{Mg}, \mathrm{Fe}) \mathrm{SiO}_{3}\right.$, hereafter abbreviated as Opx) porphyroclasts in sheared metamorphic rock, by preparing TEM specimens from petrographic thin sections using FIB and EBSD (Raimbourg et al. 2011). Following this previous work, the present study describes the result of scanning TEM (STEM) microanalysis to show the local chemical segregation at the SGBs, as well as the description of the sample preparation procedure. Finally, we discuss the implication of such chemical heterogeneities for the process of exsolution and the mobility of dislocations, using observations of microstructures in deformed Opx porphyroclasts.

\section{Methods}

The geological setting of the specimen rock, a mylonite from Hidaka Main Zone within Hidaka Metamorphic Belt, Hokkaido, Japan, was described in detail in previous papers (Raimbourg et al. 2008, 2011). In the mylonite, the predominant Opx porphyroclasts are up to a few millimeters in size and embedded in a foliated matrix of small (approximately $50 \mu \mathrm{m}$ ) plagioclase grains (Figure 1). Petrographic thin sections were prepared in the plane

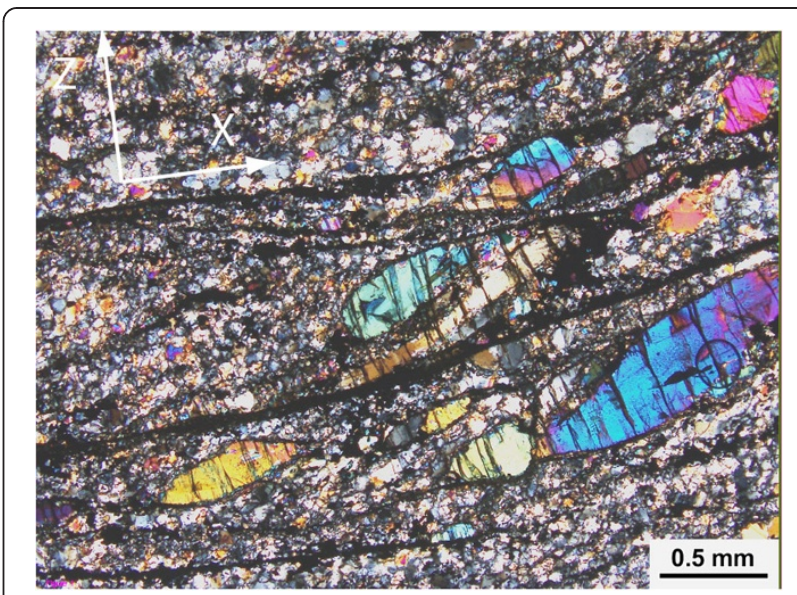

Figure 1 Cross-polarized optical micrograph of the petrographic thin section of mylonite rock cut in the $X-Z$ plane. The pole to foliation is indicated by $Z$-axis, and the lineation is indicated by $X$-axis. Spindle-like large grains are Opx porphyroclast, and the matrix is mostly made of plagioclase.

parallel to the shear direction and perpendicular to the foliation. The surfaces of the sections were polished with diamond paste then colloidal silica, and then chemical etching of the surface was carried out with hydrofluoric (HF) acid following the method described in Wegner and Christie (1985), the latter to enhance SEM imaging of SGBs and Ca-rich clinopyroxene (Cpx) lamellae exsolved in Opx along the (100) plane.

Crystal bending and/or distribution of SGBs inside Opx grains was first characterized with crystal orientation maps obtained by using a HKL Channel 5 EBSD system (Oxford Instruments, Abingdon, UK) attached to a JSM-7000 F field emission (FE)-SEM (JEOL Ltd., Tokyo, Japan). High-resolution imaging of the etched surface and determination of the crystal orientation for the FIB sample preparation were performed using a S-4500 FE-SEM (Hitachi High-technologies, Tokyo, Japan) equipped with a Noran PhaseID EBSD system (Thermo Fisher Scientific Inc., Waltham, MA, USA). The areas containing SGBs were transferred and etched to electron transparency using a Hitachi FB-2100 FIB instrument with the micro-sampling system. As described below, it is desirable that the specimens can be oriented in (S) TEM so that the incident electron beam is parallel to the $b$-axis, to which the SGBs are expected to be parallel. This was satisfied by using EBSD data. First, the EBSD pattern was acquired from the surface area of interest (Figure 2a), and the inclination of the $b$-axis from the surface normal was determined (Figure $2 b, c$ ). A 'plan-view specimen' was made by attaching the crystal fragment cut by FIB orthogonally to a crescent-shaped copper mesh for TEM, with the micro-sampling system. In this case, if the inclination of the $b$-axis was less than 


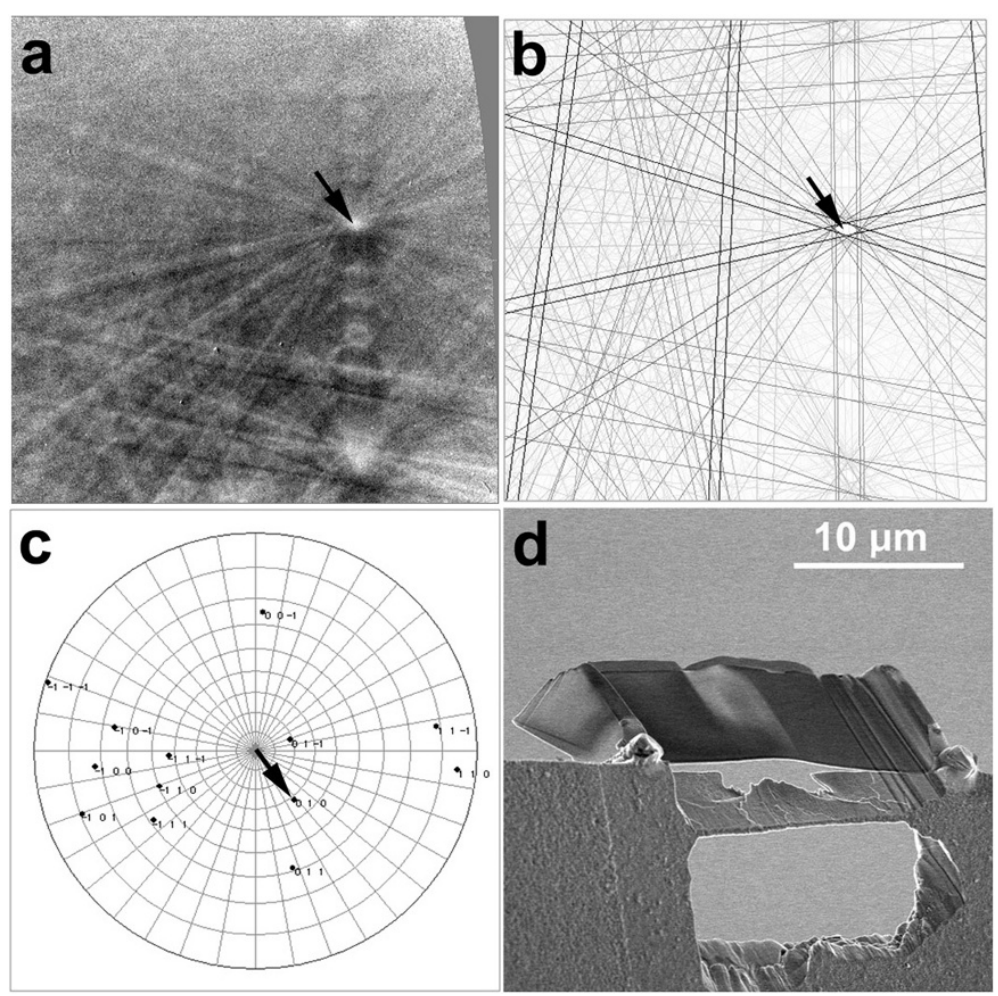

Figure 2 EBSD analysis and SEM image of a TEM specimen. (a) EBSD pattern from Opx surface and (b) corresponding drawing of Kikuchi pattern with the same crystal orientation. (c) Pole figures to show the crystal orientation of the Opx. The arrows in (a), (b), and (c) indicate the [010] (or the $b$-axis) direction. (d) SEM image of a TEM specimen prepared with the FIB micro-sampling system. Notice that the thin film was attached to the copper mesh obliquely considering the direction of the $b$-axis determined by EBSD, in order to make the incident beam parallel to the $b$-axis in TEM.

approximately $15^{\circ}$ which is the maximum tilt angle in (S) TEM, no care was necessary, but if it was over $15^{\circ}$, the fragment was attached obliquely to counter the inclination (Figure 2d).

TEM observation of the SGBs was performed using JEOL JEM-2010 UHR with the spherical aberration coefficient (Cs) of the objective lens of $0.5 \mathrm{~mm}$, operated at $200 \mathrm{kV}$. Low-magnification TEM images and selectedarea electron diffraction patterns were recorded using an ESW-500 W side-mount charge-coupled device (CCD) camera (Gatan Inc., Pleasanton, CA, USA). HRTEM images were recorded using a Gatan MSC 622 bottommount CCD camera. Elemental line profiles around dislocations and SGBs were obtained in a JEOL JEM2800 F STEM operated at $200 \mathrm{kV}$ with a Noran NSS energy dispersive X-ray spectroscopy (EDS) analysis system (Thermo Fisher Scientific Inc., Waltham, MA, USA). To achieve the atomic-scale STEM imaging of high-angle annular dark-field (HAADF), we used a JEOL ARM-200 F STEM with a cold-type field emission gun operated at $200 \mathrm{kV}$ and spherical aberration corrector (Cs-corrector) for the probe-forming lens. The noisy contrast in the STEM-HAADF images was removed using a Wiener filter (Marks 1996; Kilaas 1998) developed by K. Ishizuka (HREM-Filters Pro, HREM Research Inc., Higashimatsuyama, Japan) and implemented with Gatan DigitalMicrograph on the original images (Kogure and Okunishi 2010).

\section{Results and discussion}

\section{Electron microscopy observations}

Figure 3 is an example of EBSD analysis of deformed Opx, showing the progressive rotation of the crystal about the $b$-axis. As reported in Raimbourg et al. (2011), this rotation is mainly attained by (100) [001] dislocations in Opx. In some samples, dislocations are distributed relatively homogeneously, while in others, they organize in two ways: almost periodically arranged roughly along the (001) plane to form SGBs with misorientation up to a few degrees, and accumulated on the (100) boundaries between the exsolved Ca-rich Cpx lamellae and Opx matrix (Raimbourg et al. 2011). Chemical etching with HF on the polished surface of Opx revealed the trenched $\mathrm{Ca}$-rich $\mathrm{Cpx}$ lamellae and arrays of the etched dislocations (Figure 4a). Moreover, occasionally the lamellae are sharply bent, as seen in 

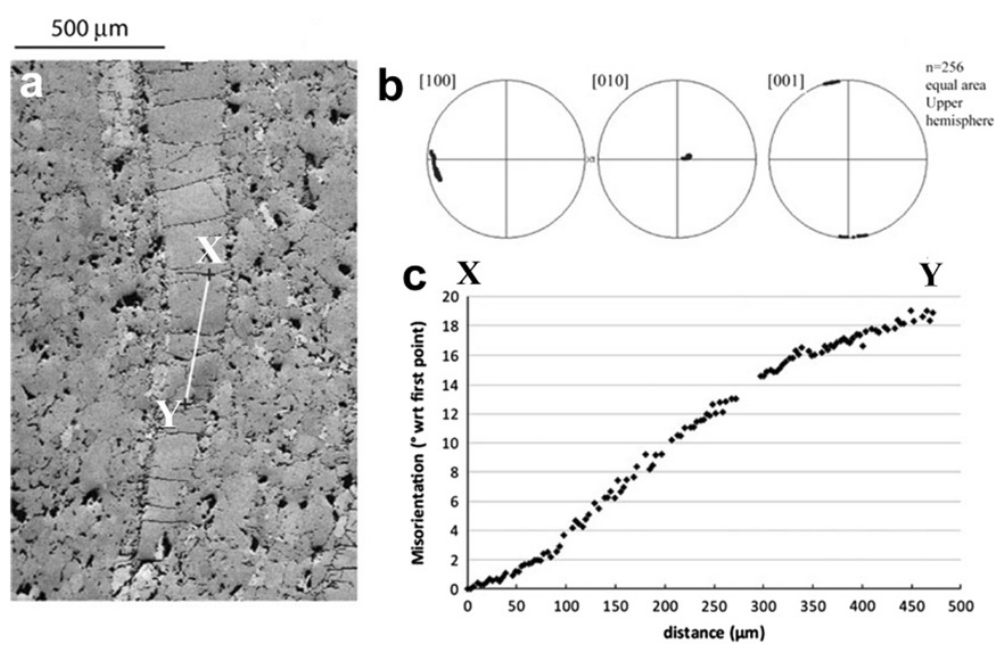

Figure 3 Example of EBSD analysis of deformed Opx. (a) Fore-scatter SEM image and (b) pole figures of the three axes for the 256 points of the Opx grain along the line $X-Y$ in (a), showing that the crystal folding is mainly formed around the $b$-axis (lineation is parallel to N-S axis of the stereographic plot and the pole of foliation parallel to the $E-W$ axis). (c) Misorientation of the crystal from the point $X$, along the line $X-Y$ in (a).

Figure $4 \mathrm{~b}$, indicating the location of higher-angle SGBs which may be semi- or incoherent.

HRTEM images of several SGBs along the $b$-axis with various misorientation angles are presented in Figure 5. The details of these images have been also described in Raimbourg et al. (2011). If the misorientation angle is small, the boundary consists of the periodic array of the (100) [001] dislocation (Figure 5a), which must correspond to the lined etch pits in Figure 3a. The HRTEM image of the single dislocation (Figure $5 \mathrm{~b}$ ) generally shows a pair of dark areas and $h 00$ lattice fringes between them, with the periodicity of a half (approximately 4.6 $\AA$ ) of that in the surrounding Opx (approximately $9.2 \AA$ ). This feature is interpreted as the dissociation of the (100) [001] dislocation into two partial dislocations and formation of clinopyroxene ( $\mathrm{Cpx}$ ) between them, as proposed by several previous works (e.g., Coe and Kirby
1975; McLaren and Etheridge 1976). The Cs-corrected STEM-HAADF image of the dislocation confirmed the formation of Cpx (Figure 6). In the image, the octahedral sites show the brightest spots as Z-contrast and the unit cells of Cpx and Opx can be drawn according to their locations. As is well known, the unit cell of Opx can be expressed as the two Cpx cells with twin relation about the (100) plane (Ito 1950). The STEM-HAADF image in Figure 6 clearly shows the relation between the Opx and $\mathrm{Cpx}$ structure around the dislocation. The image also contains the core regions of the partial dislocations as surrounded by the white circles, where the bright spots for the octahedral sites are horizontally obscured, indicating unaligned octahedral cations along the $b$-axis.

On the other hand, the SGB feature with a misorientation of $7^{\circ}$ is considerably different. The HRTEM image of the SGB (Figure 5c) shows regions indicated with

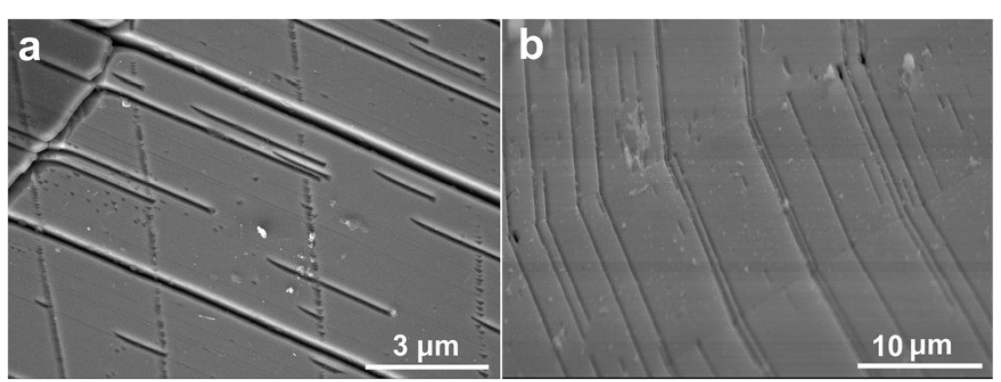

Figure 4 SEM images of polished Opx surfaces after etching with hydrofluoric acid. The straight lines are trenched lamellae of Ca-rich clinopyroxene, exsolved in Opx parallel to (100), formed by selective etching. The dislocations were also etched, showing the location of SGBs in (a). In (b), SGBs with relatively large misfit angles are identified by the sharp bend of the lamellae. 


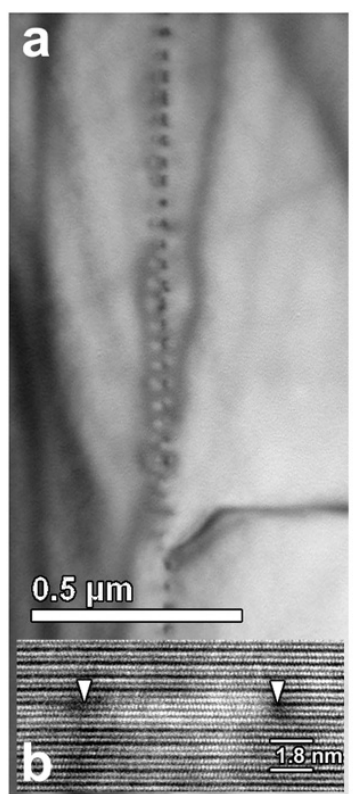

$0.8^{\circ}$

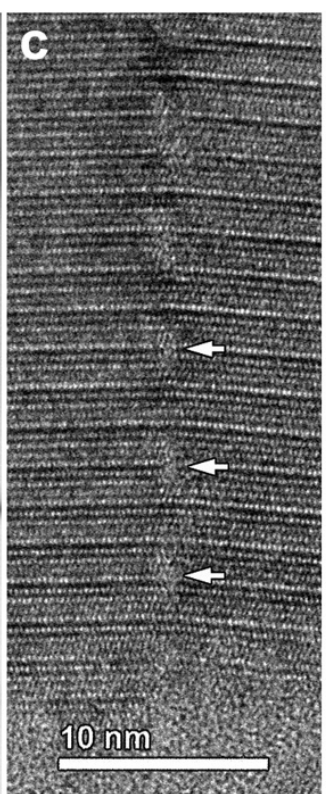

$7^{\circ}$

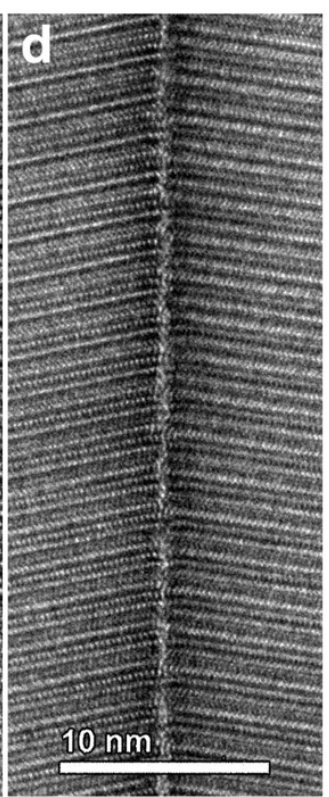

$21^{\circ}$

Figure 5 HRTEM images of SGBs in Opx, recorded along the $\boldsymbol{b}$-axis. The figures under the images indicate the misorientation (rotation) angles about the $b$-axis. (a) Bright-field image of a small-angle SGB with periodic dislocation array. (b) HRTEM image of single dislocation in (a), which dissociates into two partial dislocations as indicated with the arrowheads. Note the different periodicity of the hoo lattice fringes at the region between the partial dislocations compared to those in the surrounding Opx. (c) HRTEM image of a SGB with a misorientation angle of $7^{\circ}$. The white arrows point the regions where the lattice fringes are obscure, corresponding to dislocation cores. (d) HRTEM image of a SGB with a misorientation angle of $21^{\circ}$, indicating the completely disconnected Opx structure across the boundary.

white arrows, where the lattice fringes are obscure, arranged almost periodically along the boundary. On the contrary, the lattice fringes between these obscure regions are clear and connected across the boundary, suggesting that the Opx structure is still continuous. The averaged spacing between the adjacent regions in Figure $5 \mathrm{c}$ is roughly $50 \AA$. If we apply Frank's formula (Frank 1951), the Burgers vector around the region is $6 \AA$, which is close to the $c$-length

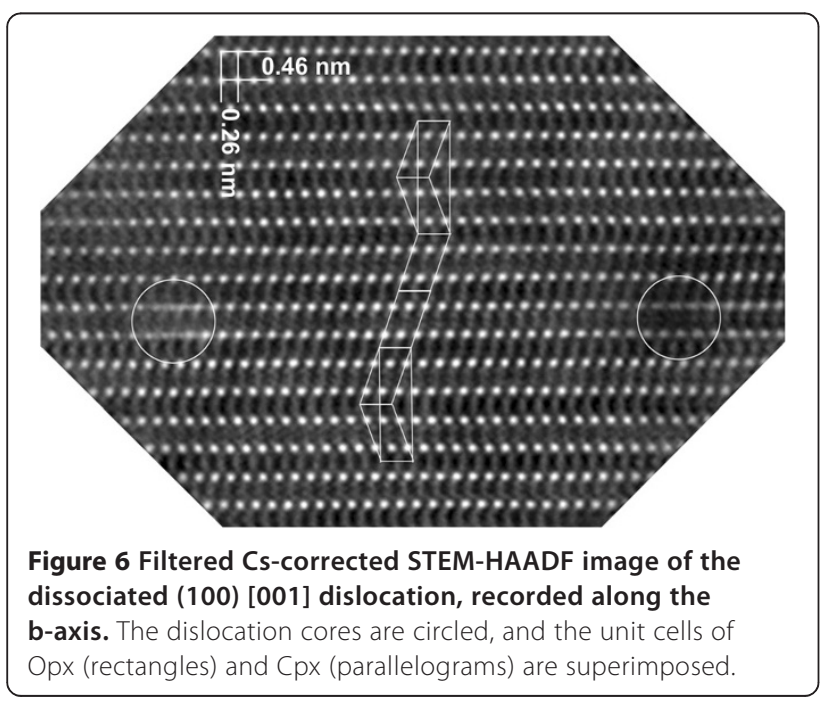

(5.2 $\AA$ ). Hence, the obscure regions are probably considered as the dislocation core of the (100) [001] dislocation without dissociation. In other words, with such a misorientation angle, SGB is 'semi-coherent' with the (100) [001] dislocation cores along the boundary. Finally, the HRTEM image of SGB with a misorientation of $21^{\circ}$ (Figure $5 \mathrm{~d}$ ) indicates the terminated lattice fringes at the boundary, and amorphous-like contrast of less than $1 \mathrm{~nm}$ thick between the fringes of Opx on both sides of the boundary. Moreover, the electron diffraction patterns (not shown) indicate that the $b$-axes of the Opx crystals on both sides are not exactly common but deviate from each other by a few tens of degrees, which results in the slightly different HRTEM contrasts between both sides of the boundary in Figure 5d. Accordingly, this SGB is considered incoherent with no structural continuity of Opx across the boundary.

The compositions in the immediate vicinity of the dislocation and SGBs were also analyzed by STEM-EDS (Figures 7 and 8). The elemental profiles along the $a$ axis and across the dislocation (Figure 7a) showed the accumulation of $\mathrm{Ca}$ and deficiency of $\mathrm{Fe}$ at the $\mathrm{Cpx}$ at the dislocation, consistent with the substitution of $\mathrm{Ca}$ for Fe in the Cpx structure (Figure 7b). The wollastonite component reaches roughly 15 to 20 at.\% at the maximum of the $\mathrm{Ca}$ profile, suggesting that $\mathrm{Cpx}$ at the 

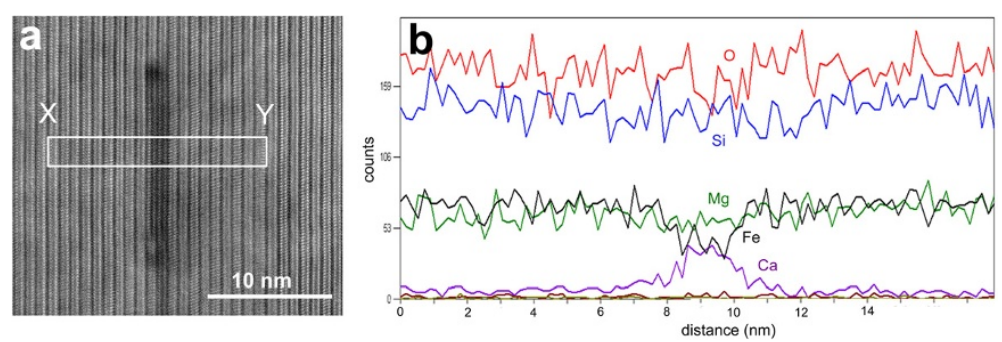

Figure 7 EDS analysis of the dislocation. (a) STEM-HAADF image of the dislocation, to show the area for the EDS analysis. (b) EDS line profile along $X-Y$, by averaging the data along the vertical direction in the rectangle in (a).

dislocation should be called augite compositionally. The chemical composition at the dislocation core did not show a distinct difference from the surroundings. The chemical composition at the high-angle SGB in Figure $5 \mathrm{~d}$ was analyzed in a similar way (Figure 8). Ca was definitely detected at the boundary, while $\mathrm{Si}$ is deficient compared to the surrounding Opx. Combined with the HRTEM image (Figure 5d), calcium-rich and silicondeficient material with thickness of a few atomic layers may exist at the boundary.

\section{Dislocation dissociation and associated chemical heterogeneity}

Many TEM works (e.g., Green and Radcliffe 1972; Kohlstedt and Vander Sande 1973; Coe and Kirby 1975; McLaren and Etheridge 1976; Van Duysen et al. 1985; Nazé et al. 1987; Steuten and Van Roermund 1989) indicated that dislocations (100) [001] of Opx are dissociated. Furthermore, the presence of Cpx between the partial dislocations was also proposed (Coe and Kirby 1975; McLaren and Etheridge 1976; Nazé et al. 1987). In the present study, STEM-HAADF imaging (Figure 6) has clearly confirmed the presence of a Cpx structure. In addition, our EDS analysis has shown considerable chemical difference between the $\mathrm{Cpx}$ structure and surrounding $\mathrm{Opx}$ with enrichment

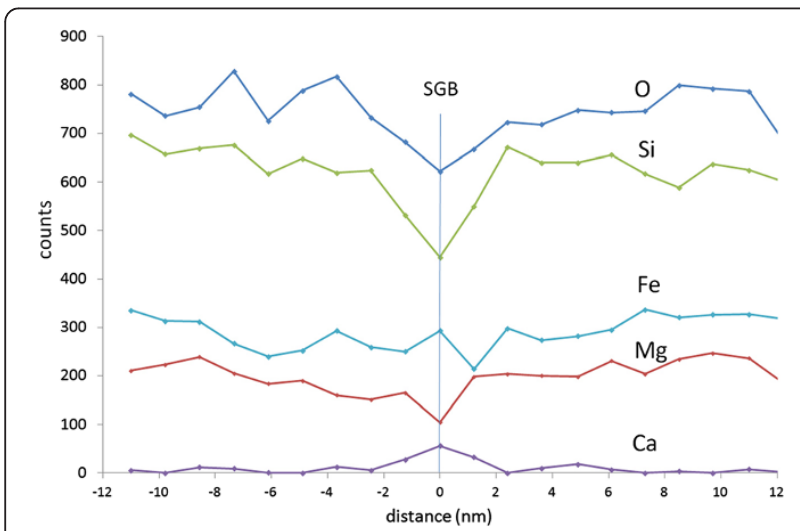

Figure 8 EDS line profile across the high-angle SGB in Figure 5d. Obtained in a similar way to that in Figure 7. in $\mathrm{Ca}$ and depletion in Fe for Cpx. This chemical heterogeneity may have a considerable influence on the plasticity of Opx porphyroclasts because the glide of the dislocation requires the chemical heterogeneity to be moved along. In other words, chemical diffusion of calcium and iron necessarily occurs as dislocation is gliding and therefore causes a potential limitation to this motion. This does not seem to be the case here, as the Opx porphyroclasts are strongly deformed (Raimbourg et al. 2008) showing that chemical diffusion is not a process which limits plastic deformation at granulite-facies conditions, i.e., at high temperature. However, the deactivation of dislocation slip with decreasing temperature may be the consequence of sluggish chemical diffusion. Besides, it is suspected that such a dislocation with the structure and chemistry close to Ca-rich $\mathrm{Cpx}$ can be nucleation sites of the Ca-rich exsolution lamellae, as suggested by White and Mawer (1988). Actually, the dense Ca-rich exsolution lamellae are found only in the strongly elongated porphyroclasts within the shear zones and absent in the surrounding undeformed porphyroclasts, indicating the interplay between deformation (by dislocation creep) and exsolution, which is also common in feldspar deformed at granulite grade conditions (White and Mawer 1988).

Flux of calcium in the SGBs and relevant recrystallization

Another accumulation of calcium has been also found in the high-angle incoherent SGB in Figure 5d (Figure 8). This result is the direct evidence for the hypothesis that such incoherent SGBs are the major diffusion pathways of calcium during deformation. Several macroscopic structures in the deformed Opx can be accounted for by this hypothesis (Figure 9). In Figure 9a, small Ca-rich Cpx grains other than the lamellae are developed along the high-angle SGB. Furthermore, the Cpx lamellae are absent around another high-angle SGB in Figure 9b, indicating the depletion of calcium in Opx around the SGB. On this example, a simple mass balance calculation shows that SGBs not only segregate Ca but also enhance $\mathrm{Ca}$ diffusion along the boundary. On the surface of the host Opx far from the SGB in Figure 9b, for instance, at 

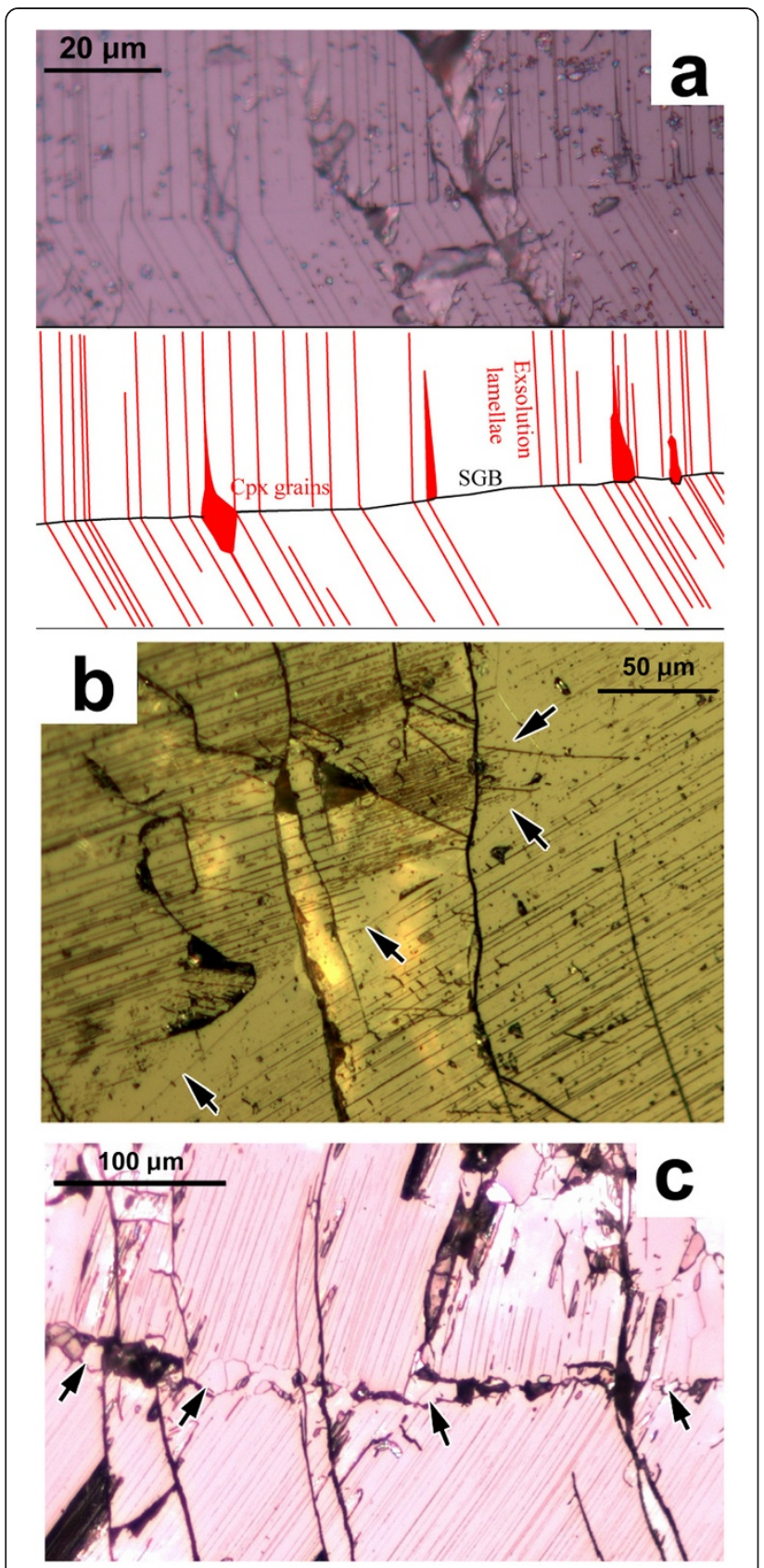

Figure 9 Relationship between SGBs and exsolutions. All Opx surfaces have been polished, then chemically etched to reveal Ca-rich Cpx exsolution lamellae and SGBs. SGBs are also apparent through the rotation of lamellae. (a) Cpx grains formed along a SGB, merging with exsolution lamellae. (b) On both sides of the SGB (arrowed), exsolution lamellae are absent. (c) Recrystallization of small, exsolution-free Opx grains (arrowed) along a SGB. All pictures were taken by an optical microscope in reflected light.

the bottom-right of the figure, the density of Ca-rich exsolution lamellae is approximately 0.26 lines per micrometer if measured across the lamellae. The thickness of these lamellae is very variable, as can be seen in the various
TEM pictures in Raimbourg et al. (2011), and we consider $10 \mathrm{~nm}$ as a minimum value. Consequently, the volume ratio of exsolution to Opx is more than $2.6 \times$ $10^{-3}$. The area depleted of exsolution, on both sides of the SGB, has a minimum thickness of $10 \mu \mathrm{m}$ in Figure 9b. Hence, if $\mathrm{Ca}$ in the area depleted of exsolution around the SGB is only accumulated and stored at the boundary, it should form Ca-rich exsolution of more than $26 \mathrm{~nm}$ thick at the boundary. The actual thickness of the Ca-rich region at SGBs is far smaller than this as shown in Figure 8, indicating that $\mathrm{Ca}$ has flown out of the host Opx along the SGB.

In parallel, the zones around the high-angle SGB free from exsolution lamellae are preferential sites for recrystallization of small grains (Figure 9c). The process of recrystallization definitely involves the formation of SGBs and their evolution into true GBs with increasing misorientation (Raimbourg et al. 2011). As described above, SGBs in Opx can be started by the regular arrangement of the (100) [001] dislocations. However, another slip system should be activated for the recrystallization shown in Figure 9c. Exsolution lamellae of Cpx densely distributed within Opx probably act as barriers to the glide of any dislocation except in the (100) plane (i.e., parallel to the lamellae), hence preventing recrystallization. Enhanced recrystallization at the SGB in Figure 9c may therefore be interpreted as the activation of multiple slip systems where exsolution lamellae are absent.

\section{Conclusions}

State-of-the-art electron beam analyses with atomic-scale resolution have imaged unit cell structure of the (100) [001] dislocation to form SGBs, as well as high-angle incoherent SGBs in deformed Opx porphyroclasts in mylonite. The Cpx structure is definitely formed between the dissociated partial dislocations and contains considerable amounts of calcium replacing iron. Although more investigation is needed, such a Cpx structure may link the deformation and exsolution in the Opx as the nucleus of the exsolution. High-angle, incoherent SGBs probably contain an amorphous-like material of a few atomic layers enriched in calcium. Probably, this is the evidence for the idea that the incoherent SGBs act as diffusion pathways of calcium and maybe other elements. Accordingly, development of SGBs by deformation also accelerates chemical re-equilibrium of minerals during metamorphic processes. These nanostructures of SGBs will be a key to understand deformation, grain size reduction, and mechanical weakening of rocks in ductile shear zones.

\section{Abbreviations}

CCD: charge-coupled device; Cpx: clinopyroxene; Cs: spherical aberration coefficient; EBSD: electron backscatter diffraction; EDS: energy dispersive X-ray spectroscopy; FE: field emission; FIB: focused ion beam; GB: grain boundary; HAADF: high-angle annular dark-field; HRTEM: high-resolution 
transmission electron microscopy; Opx: orthopyroxene; SEM: scanning electron microscopy; SGB: subgrain boundary; STEM: scanning transmission electron microscopy; TEM: transmission electron microscopy.

\section{Competing interests}

The authors declare that they have no competing interests.

\section{Authors' contributions}

TK conducted this study; carried out the SEM, EBSD, and TEM analyses; interpreted the data; and prepared the manuscript. HR collected rock samples, prepared petrographic thin sections, performed SEM-EBSD analyses, and joined the preparation of the manuscript. AK carried out the HAADF imaging and $\mathrm{X}$-ray microanalysis in STEM, and gave the interpretation of the images and analysis. EF prepared TEM/STEM specimens using FIB and suggested the technique used to prepare these specimens. Finally, Yl gave several valuable comments for the interpretation of TEM/STEM results from his deep background of grain boundaries. All authors read and approved the final manuscript.

\section{Acknowledgements}

This work was supported by Grants-in-Aid for Scientific Research from MEXT of Japan (21107005). A part of this work was conducted in Research Hub for Advanced Nano Characterization, The University of Tokyo and supported by 'Nanotechnology Platform' (Project No. 12024046), both sponsored by MEXT, Japan.

\section{Author details}

'Department of Earth and Planetary Science, Graduate School of Science, The University of Tokyo, 7-3-1 Hongo, Bunkyo-ku, Tokyo 113-0033, Japan. ${ }^{2}$ Institut des Sciences de la Terre d'Orléans, University of Orléans, 1a rule de la Férollerie, Orléans 45071, France. ${ }^{3}$ Institute of Engineering Innovation, School of Engineering, The University of Tokyo, 2-11-16 Yayoi, Bunkyo-ku, Tokyo 113-8656, Japan.

Received: 10 January 2014 Accepted: 23 July 2014

Published: 4 August 2014

\section{References}

Boullier AM, Gueguen Y (1975) SP-mylonites: origin of some mylonites by superplastic flow. Contrib Mineral Petrol 50:93-104

Braun J, Chery J, Poliakov A, Mainprice D, Vauchez A, Tommasi A, Daigniers M (1999) A simple parameterization of strain localization in the ductile regime due to grain size reduction: a case study for olivine. J Geophys Res 104 (B11):25167-125181

Coe RS, Kirby SH (1975) The orthoenstatite to clinoenstatite transformation by shearing and reversion by annealing: mechanism and potential applications. Contrib Mineral Petrol 52:29-55

Fitz Gerald JD, Etheridge MA, Vernon RH (1983) Dynamic recrystallization in a naturally deformed albite. Textures Microstructures 5:219-237

Frank FC (1951) The resultant content of dislocations in an arbitrary intercrystalline boundary. In: A symposium on plastic deformation of crystalline solids. Mellon Institute, Pittsburgh, p 150

Furusho M, Kanagawa K (1999) Transformation-induced strain localization in a Iherzolite mylonite from the Hidaka metamorphic belt of central Hokkaido, Japan. Tectonophysics 313:411-432

Green HWII, Radcliffe SV (1972) Deformation mechanisms in olivine and flow in the upper mantle. Earth Planet Sci Lett 15:239-247

Guillopé M, Poirier JP (1979) Dynamic recrystallization during creep of single-crystalline halite: an experimental study. J Geophys Res 84(B10):5557-5567

Heinemann S, Wirth R, Gottschalk M, Dresen G (2005) Synthetic [100] tilt grain boundaries in forsterite: $9.9^{\circ}$ to $21.5^{\circ}$. Phys Chem Miner 32:229-240

Hirth G, Tullis J (1992) Dislocation creep regimes in quartz aggregates. J Struct Geol 14:145-159

Ito T (1950) X-ray studies on polymorphism. Maruzen, Tokyo

Kamino T, Yaguchi T, Hashimoto T, Ohnishi T, Umemura K (2005) A FIB micro-sampling technique and a site specific TEM specimen preparation method. In: Giannuzzi LA, Stevie FA (ed) Introduction to focused ion beams: instrumentation, theory, techniques and practice. Springer, New York, p 229

Kilaas R (1998) Optimal and near-optimal filters in high-resolution electron microscopy. J Microsc 190:45-51
Kogure T, Okunishi E (2010) Cs-corrected HAADF-STEM imaging of silicate minerals. J Electron Microsc 59:263-271

Kohlstedt DL, Vander Sande JB (1973) Transmission electron microscopy investigation of the defect microstructure of four natural orthopyroxenes. Contrib Mineral Petrol 42:169-180

Marks LD (1996) Wiener-fiter enhancement of noisy HREM images. Ultramicroscopy 62:43-52

McLaren AC, Etheridge MA (1976) A transmission electron microscope study of naturally deformed orthopyroxene. I. Slip mechanisms. Contrib Mineral Petrol 57:163-177

McLaren AC, Etheridge MA (1980) A transmission electron microscope study of naturally deformed orthopyroxene. II: mechanisms of kinking. Bull Miner 103:558-563

Nazé L, Doukhan N, Doukhan J-C, Latrous K (1987) A TEM study of lattice defects in naturally and experimentally deformed orthopyroxenes. Bull Miner 110:497-512

Poirier JP (1980) Shear localization and shear instability in materials in the ductile field. J Struct Geol 2:135-142

Poirier JP (1995) Plastic rheology of crystals. In: Ahrens TJ (ed) Mineral physics and crystallography: a handbook of physical constants. AGU, Washington DC, pp 237-247

Poirier JP, Nicolas A (1975) Deformation-induced recrystallization due to progressive misorientation of subgrains, with special reference to mantle peridotites. J Geol 83:707-720

Precigout J, Gueydan F, Gapais D, Garrido CJ, Essaifi A (2007) Strain localisation in the subcontinental mantle - a ductile alternative to the brittle mantle. Tectonophysics 445:318-336

Raimbourg H, Toyoshima T, Harima Y, Kimura G (2008) Grain size reduction mechanisms and rheological consequences in high-temperature gabbro mylonites of Hidaka, Hokkaido. Earth Planet Sci Lett 267:637-653

Raimbourg H, Kogure T, Toyoshima T (2011) Crystal bending, subgrain boundaries development and recrystallization in orthopyroxene during granulite-facies deformation. Contrib Mineral Petrol 162:1093-1111

Read WT (1953) Dislocations in crystals. McGraw-Hill, New York

Rice JR (1976) The localization of plastic deformation. In: Koiter WT (ed) Theoretical and applied mechanics. North-Holland Publishing Co., Delft, pp 207-220

Steuten JM, Van Roermund HLM (1989) An optical and electron microscopy study of defect microstructures in naturally deformed orthopyroxene. Tectonophysics 157:331-338

Van Duysen JC, Doukhan N, Doukhan JC (1985) Transmission electron microscope study of dislocations in orthopyroxene $(\mathrm{Mg}, \mathrm{Fe}){ }_{2} \mathrm{Si}_{2} \mathrm{O}_{6}$. Phys Chem Miner 12:39-44

Wegner MW, Christie JM (1985) Chemical etching of amphiboles and pyroxenes. Phys Chem Miner 12:86-89

White S (1977) Geological significance of recovery and recrystallization processes in quartz. Tectonophysics 39:143-170

White JC, Mawer CK (1988) Dynamic recrystallization and associated exsolution in perthites: evidence of deep crustal thrusting. J Geophys Res 93(B1):325-337

doi:10.1186/1880-5981-66-84

Cite this article as: Kogure et al: Subgrain boundary analyses in deformed orthopyroxene by TEM/STEM with EBSD-FIB sample preparation technique.

Earth, Planets and Space 2014 66:84.

\section{Submit your manuscript to a SpringerOpen ${ }^{\circ}$ journal and benefit from:}

- Convenient online submission

- Rigorous peer review

- Immediate publication on acceptance

- Open access: articles freely available online

- High visibility within the field

- Retaining the copyright to your article

Submit your next manuscript at $>$ springeropen.com 